http://jmscr.igmpublication.org/home/

ISSN (e)-2347-176x ISSN (p) 2455-0450

crossref DOI: https://dx.doi.org/10.18535/jmscr/v9i9.08

Journal Of Medical Science And Clinical Research

IGM Publication

An Official Publication of IGM Publication

\title{
Prevalence of Pre-Diabetes and Diabetic status in Pre-Hypertensive Patients
}

\author{
Author
}

\section{Dr Mrinal Kanti Guha}

Apollo Clinic, 26, Diamond Harbour Road, Kolkata, India

\begin{abstract}
Background: Diabetes and hypertension are something that coexist in patients. The prevalence of hypertension is 1.5-2 times more in those with diabetes than in those without diabetes, whereas almost 1/3 of the patients with hypertension develop diabetes later. In this study, pre-diabetes and diabetes in hypertensive patients and on coexisting risk factors were studied.

Methods: After diagnosed hypertension cases on treatment who gave written informed consent were studied for duration of disease, drug therapy, family history, manifestations of co-morbidities and investigated for fasting and post-prandial blood sugar, oral glucose tolerance, lipid profile, serum creatinine, uric acid and SGPT.

Results: Out of 100 recruited hypertensive patients 52 were females and 48 were males. $43 \%$ were diagnosed pre-diabetics whereas $16 \%$ were diabetics.

Conclusions: Prediabetes and diabetes are highly prevalent among individuals with known cases of hypertension and pre-hypertension.

Keywords: Pre-diabetes, Impaired glucose tolerance, Impaired fasting glucose, Diabetes, Hypertension, Pre-Hypertensive.
\end{abstract}

\section{Introduction}

Hypertension and diabetes, two of the major global risks for mortality, are on a rapid rise in developing nations. ${ }^{1}$ In India, according to the 2011 estimates reported by the Indian council of medical research-India diabetes study, 62.4 and 77.2 million people have diabetes mellitus (DM) and pre-diabetes (PD), respectively. ${ }^{2}$ It is predicted that by 2030, India's diabetes burden will be almost 87 million people. ${ }^{3}$ Additionally, there is increasing prevalence of hypertension in the Indian population, especially in the urban areas. ${ }^{4}$ Elevated blood pressure has been linked to ischemic heart disease, peripheral vascular diseases, stroke, myocardial infarction, and renal failure. ${ }^{5}$ Hypertension and diabetes are two most important risk factors for cardiovascular disease. Given the increasing rates of coronary artery disease among Indians, especially at a younger age, understanding and successfully managing hypertension and diabetes may hold the key to reducing cardiovascular mortality in India. ${ }^{6}$

Diabetes and hypertension are also known to coexist in patients. The prevalence of hypertension is $1.5-2$ times more in those with diabetes than in those without diabetes, whereas almost $1 / 3$ of the patients with hypertension develop diabetes later. ${ }^{7}$ This coexistence presents an increased risk and can accelerate vascular complications. ${ }^{8,9}$ Diabetes and hypertension are manageable health conditions and can be controlled by medicinal intervention, exercise, and 
diet. Moreover, detection of progenitors prediabetes and pre-hypertension through periodic surveillance can allow for early intervention and delay disease progression. Although studies have been carried out over the past few years to estimate the prevalence of diabetes and hypertension, they were often small-scale and regional or carried out in a particular subset of the diverse Indian population.

In this research, we present the findings on prevalence of new cases of pre-diabetes and diabetes, diabetes in hypertensive patients and on coexisting risk factors. The objectives of the study were following.

○ To determine the prevalence of prediabetes and diabetic status in hypertensive patients and its early detection.

- To study correlation of duration of hypertension leading to pre-diabetes and diabetic status

- To study the correlation of impaired plasma glucose levels with lipid profile, serum uric acid, SGPT and co-morbidities.

\section{Methods}

This study is a transverse sectional study of patients attending OPD in a private Clinic in Kolkata, West Bengal (Eastern India). Patients who gave written informed consent were selected for this study $(n=100)$.

\section{Inclusion Criteria}

Patients more than 40 years of age who are diagnosed cases of hypertension and are taking treatment for the same.

\section{Exclusion Criteria}

Patients less than 40 years of age, known cases of DM and secondary hypertension, pregnant ladies and patients on thiazide diuretics or beta blockers. Demographic details of patients, history of hypertension, drug therapy, family history and history of co-morbidities were noted. Patients were investigated for fasting and post-prandial plasma glucose, lipid profile, serum uric acid, serum glutamate pyruvate transaminase (SGPT) and serum creatinine levels. In addition to this patients were subjected to oral glucose tolerance test (OGTT).

\section{Definitions}

A patient whose diabetic status was not known and had OGTT ( 2 hours) levels between 140 $\mathrm{mg} / \mathrm{dl}$ and less than $200 \mathrm{mg} / \mathrm{dl}$ or fasting plasma glucose levels between 100 and $125 \mathrm{mg} / \mathrm{dl}$ was defined as having ' 'prediabetes.' Patients without previously reported diabetes who had OGTT (2 hours) levels more than $200 \mathrm{mg} / \mathrm{dl}$ were considered as new cases of diabetes mellitus (DM).

\section{Statistical Analysis}

Categorical data is presented as percentages and continuous data as mean and standard deviations.n Significance of difference in parameters was calculated by Karl Pearson's Chi Square test at 95\% confidence interval (p\&lt;0.05). EpiInfo version 7.0 (public domain software package from centers for disease control and prevention was used for calculating the Chi Square test (with Yates' correction where applicable).

\section{Results}

Out of 100 recruited hypertensive patients 52 were females and 48 were male patients. When these patients were screened for pre-diabetes and diabetes, $43 \%$ were diagnosed as prediabetics where as $16 \%$ were diabetics. Amongst those who were detected to be prediabetic, 58\% were females and $42 \%$ were male. In diabetic patients $44 \%$ were female and $56 \%$ were male. The demographic details of demography and investigations of patients are given in Table 1. The details of diabetics are in Table 2 and those of prediabetics in Table 3. 
Table1: Hypertensives-demographic profile and blood parameters

\begin{tabular}{|c|c|c|c|c|}
\hline \multicolumn{5}{|c|}{ Duration of hypertension (years) } \\
\hline & & $\begin{array}{c}<1 \\
\text { year }\end{array}$ & $\begin{array}{c}1-5 \\
\text { year }\end{array}$ & $\begin{array}{c}>5 \\
\text { year }\end{array}$ \\
\hline & $21-40$ & 11 & 2 & 1 \\
\hline \multirow[t]{2}{*}{ Age } & $41-60$ & 22 & 27 & 17 \\
\hline & $>60$ & 4 & 7 & 9 \\
\hline \multirow[t]{2}{*}{ Gender } & Female & 20 & 18 & 14 \\
\hline & Male & 17 & 18 & 13 \\
\hline Family & No & 34 & 33 & 26 \\
\hline History of hypertension & Yes & 3 & 3 & 1 \\
\hline Serum & Normal & 18 & 23 & 16 \\
\hline Triglycerides & Increased & 19 & 13 & 11 \\
\hline Serum & Normal & 25 & 24 & 21 \\
\hline \multirow[t]{2}{*}{ cholesterol } & Increased & 12 & 12 & 6 \\
\hline & Normal & 30 & 25 & 19 \\
\hline Serum LDL & Increased & 7 & 11 & 8 \\
\hline Serum & Normal & 34 & 33 & 25 \\
\hline creatinine & Increased & 3 & 3 & 2 \\
\hline Serumuric & Normal & 32 & 27 & 19 \\
\hline acid & Increased & 5 & 9 & 8 \\
\hline
\end{tabular}

Table 2: Serum parameters normal and raised fasting plasma glucose

\begin{tabular}{|c|c|c|c|c|}
\hline \multicolumn{5}{|c|}{ Fasting plasma glucose $(\mathrm{mg} / \mathrm{dl})$} \\
\hline & & $<100$ & $<125$ & $>125$ \\
\hline Family history & No & 50 & 29 & 15 \\
\hline of diabetes mellitus & Yes & 2 & 4 & 0 \\
\hline Serum & Normal & 49 & 29 & 14 \\
\hline \multirow[t]{2}{*}{ creatinine } & Increased & 3 & 4 & 1 \\
\hline & Normal & 39 & 25 & 10 \\
\hline Serum LDL & Increased & 13 & 8 & 5 \\
\hline Serum & Normal & 36 & 22 & 12 \\
\hline cholesterol & Increased & 16 & 11 & 3 \\
\hline Serum & Normal & 33 & 16 & 8 \\
\hline triglycerides & Increased & 19 & 17 & 7 \\
\hline Serumuric & Normal & 39 & 25 & 14 \\
\hline acid & Increased & 13 & 8 & 1 \\
\hline
\end{tabular}

Table 3: Serum parameters -normal and raised plasma glucose after 2 hour OGTT

\begin{tabular}{|l|c|c|c|c|}
\hline \multicolumn{2}{|l|}{ hours OGTT plasma glucose $(\mathrm{mg} / \mathrm{dl})$} & \multicolumn{4}{l|}{} \\
\hline & & $<140$ & $<200$ & $>200$ \\
\hline Serum LDL & Normal & 39 & 26 & 9 \\
\hline & Increased & 13 & 8 & 5 \\
\hline Serum & Normal & 48 & 33 & 11 \\
\hline creatinine & Increased & 4 & 1 & 3 \\
\hline Serum & Normal & 37 & 22 & 11 \\
\hline cholesterol & Increased & 15 & 12 & 3 \\
\hline Serum & Normal & 29 & 20 & 8 \\
\hline triglycerides & Increased & 23 & 14 & 6 \\
\hline Serumuric & Normal & 36 & 29 & 13 \\
\hline acid & Increased & 16 & 5 & 1 \\
\hline
\end{tabular}

\section{Discussion}

Among the high blood pressure patients of UNTH, the ore-diabetic status was 25 percent. It comes within the range that had been forwarded by
Govindarajan et al. 2 Prevalence rate of hypertension for about 43 percent had been found in urban areas of India. 4 Furthermore, Milla and Grant had claimed that 25 percent of the total population 
were at the risk of relative insulin resistance that often leads to type 2 Diabetes Mellitus. 6 In Kolkata, a prevalence rate of 3.5 percent was reported among primary health care patients while 40 percent women had polycystic ovarian syndrome. Despite a whopping 18 percent of Indian adults being aware of the occurrences of prediabetes, only 4 percent were aware of it. During this study, awareness had not been examined and it was found that lack of knowledge regarding prediabetes in an individual makes it mandatory that screening must be done. Impaired fasting glucose (IFG) was more prevalent among the patients $15 \%$, than impaired glucose tolerance (IGT) (5\%). This does not, however, align with the findings of the report by Shobha et al. where 9.7 percent of IFG and 15.6 percent of IGT was prevalent amonf Indians who aged between 40 to 74 years. This article had also found that the prevalence combined rate of both IFG and IGT in India was 14.7 among adults of 45-74 years, and 30.7 percent among women and men from 40-49 and 50-59 years.

While detecting early dysregulation, IGT tends to be more sensitive as compared to the IFG. This is reflective of hepatic gluconeogenesis and also a slow uptake of glucose from the blood of the adipose tissue and skeletal muscles after a meal. It has independent association with traditional microvascular complications of diabetes. However, it is noteworthy that not all IGT patients would progress to diabetes as it is a reversible and dynamic state. While some revert towards normoglycaemia, a majority of the patients would continue in the same state. 6 patients out of the entire sample had both IGT and IFG impaired.

Eleven patients were impaired with IGT in this study, among whom 5 had IGT alone while 6 had both IGT and IFG. These eleven patients were at an increased threat of a progression towards Type 2 Diabetes Mellitus and develops cardiovascular disorders. 14 percent of the patients had unreported about Diabetes Mellitus. Hence, it underscores the importance of regular screening of the hypertensive patients for checking DM. The mean HOMA-IR (homeostasis model assessment for insulin resistance) of the patients, $(5.1+4.5)$ is in the upper range of values reported for PD (4.3-5.2) with some definitely in the DM range, 8.3-9.5, as a result of the unreported DM subjects. The HOMA-IR of the total sample exceeded the range of values which is usually reported for Indians i.e., 2.1-2.7. In comparison to this, the occurrence of PD amongst the patients had not exceeded the value range. However, the percentage of underreported cases was indeed high. The reasons behind unreporting included lack of affordability of health services and also ignorance. There does not exist any relationship between laboratory parameters and anthropometric parameters which was evident from the following. This holds back from predicting PD based on the knowledge of former parameters. As for the patients, they held not much differences amongst themselves in their Body Mass Index (BMI). But they were different in case of the waist circumference and the waist to hip ratio. The differences in the later parameters reflect in considerably ascended fasting and 2-hour post prandial plasma glucose of the patients. This depicts that BMI is not a good index for detecting obesity in this group of patients. Among hypertensive patients, normal fasting insulin level showcase the observation that majority of the patients could secrete insulin which was enough for them to be kept in normoglycaemic state, even in the absence of insulin resistance as revealed by the normal index. The study has identified that the importance of screening for PD especially among hypertensive patients of the study locality.

\section{Conclusion}

Prediabetes and diabetes are extremely popular among people with known cases of hypertension. The threat of both diabetes and prediabetes increased in long standing hypertension. According to this study, it has highlighted the importance of screening for prediabetes and diabetes especially among hypertensive patients of the study locality so that treatment measures can be started early on these patients and further complications can be prevented by the disease. 


\section{References}

1. Colagiuri S, Borch-Johnsen K, Glumer C. There really is an epidemic of Type 2 Diabetes. Diabetologia. 2005; 48(8): 14591463.

2. World Health Organisation. Geneva: Factfile; 2014. Available from: http://www.who.int/features/factfiles/diabete s/en

3. Wild S, Roglic G, Green A, Sicree R, King H. Global prevalence of Diabetes: Estimates for the year 2000 and projections for 2030. Diabetes Care. 2004; 27: 1047-53.

4. Gale J. India\&\#39;s Diabetes Epidemic Cuts Down Millions Who Escape Poverty. Bloomberg;2010 (Retrieved 8 June 2012). Available from: http://www.bloomberg.com/news/2010-1107/India\&\#39; deadly Diabetes scourge cuts down millions rising to middle class.html

5. World Health Organization. The WHO STEPwise approach to Surveillance of noncommunicable diseases (STEPS) [Internet]. 2003 [cited 12 Sep 2017]. Available: http://www.who.int/ncd_surveilla nce/en/steps_framework_dec03.pdf

6. Sixty-sixth World Health Assembly. Followup to the Political Declaration of the Highlevel Meeting of the General Assembly on the Prevention and Control of Noncommunicable Diseases WHA 66.10. 2013 [Internet]. 2013 [cited 23 Nov 2016]. Available: http://apps.who.int/gb/ebwha/pdf _files/WHA66/A66_R10-en.pdf

7. Diabetes Prevention Programme Research Group. Reduction in the incidence of type 2 diabetes with lifestyle intervention or metformin. N Engl J Med. 2000;346(6):393463.

8. Chiasson JL, Gomis R, Hanefeld M, Josse RG, Karasik A, Laakso M. The STOP NIDDM Trail: an international study on the efficacy of alphaglucosidase inhibitor to prevent type 2 diabetes in a population with impaired glucose tolerance: rationale, design and preliminary screening data. Study to Prevent Non-Insulin Dependent Diabetes Mellitus. Diabetes Care. 1998;21(10):17205.

9. Hiltunen L, Laara E, Keinane-Kuikaaniemi S. Changes in glucose tolerance during a three year's follow-up in an elderly population. Public Health. 1999;13(2):181-4.

10. Chen K, High L. Prevalence of impaired fasting glucose and type 2 diabetes mellitus in Benghu Islets, Taiwan: evidence of a rapidly emerging epidemic. Diab Res ClinPract. 2009;44(1):59-69.

11. American Diabetes Association. Standards of medical care indiabetes - 2008. Diabetes Care. 2008;31(Suppl 1):S12-54.

12. Rolka DR, Burrows NR, Li Y, Geiss LS. Selfreported prediabetes and risk-reduction activitiesUS-2006. JAMA. 2009;301(6):5913.

13. Anjana R, Pradeepa R, Deepa M, Datta M, Sudha V, Unnikrishnan R, et al. Prevalence of diabetes and prediabetes (impaired fasting glucose and/or impaired glucose tolerance) in urban and rural India: Phase I results of the Indian Council of Medical ResearchIndia DIABetes (ICMR-INDIAB) study. Diabetologia. 2011;54(12):3022-7.

14. Shrestha UK, Singh DL, Bhattarai MD. The prevalence of hypertension and diabetes defined buy fasting and 2 hour plasma glucose criteria in urban Nepal. Diabetes Medicine. 2006;23(10):1130-5.

15. Shaw J, Sicree R, Zimmet P. Global estimates of the prevalence of diabetes for 2010 and 2030. Diabetes Res ClinPract. 2010;87:4-14. 